\title{
Cross-cultural L2 learning exchange: A qualitative examination of strategies, tools, cognition and translation outcomes
}

\author{
Robert W. Elliott ${ }^{1}$, Xiaolei Chen ${ }^{2}$ \\ ${ }^{1}$ Foreign Language School, Linyi University, China \\ ${ }^{2}$ Linyi Writer's Association, China
}

\begin{tabular}{l} 
Article Info \\
\hline Article history: \\
Received Jul 11, 2019 \\
Revised Aug 15, 2019 \\
Accepted Aug 29, 2019 \\
\hline
\end{tabular}

Keywords:

Adult L2 acquisition

Cognition

Language applications

Translation

\begin{abstract}
Amidst the milieu of free and at-cost L2 language software applications coming into existence for use on mobile devices and computers, adult L2 learners are faced with the challenge of selecting their best choice for them to use in acquiring a specific second language. Their selection is based on their individual need and the context in which they plan to use the second language. More importantly, it is well known there is no single tool, resource, or strategy that adult L2 learners can use to fully acquire a second language quickly and effectively, especially for intercultural couples who lack a common language for daily communication. While there is much literature on the topic of L2 acquisition and learning, the purpose of this auto-ethnographic study is to share with readers specific aspects of our journey in acquiring each other's native language throughout their first year together. Included are subsequent findings involving cognition and translation issues as developing skills recognized during various phases of L2 acquisition.
\end{abstract}

Copyright $\odot 2019$ Institute of Advanced Engineering and Science. All rights reserved.

\section{Corresponding Author:}

Robert W. Elliott

Foreign Language School,

Linyi University,

Middle Shuangling Road, Linyi, Shandong, China 276005

Email: rbrt_lltt@yahoo.com

\section{INTRODUCTION}

In the context of this study, intercultural relationships bring about a unique set of challenges and successes especially for a married couple that possesses very limited second language communication skills in the target languages. What we believe is quite common for interracial married couples who do not speak each other's language very well is their innate desire to help each other improve their skills and abilities in each other's native language, while they want earnestly to develop their individual language skills in our new second language. The purpose of this self-autoethnography is to share much insight into the challenges and strategies that "we," referred to in third-person hereafter, used to acquire and learn each other's native language through our own perspectives after having reviewed and made strong connections with the language acquisition theories and best practices found throughout the literature that are presented in the literature review. In doing so, this study will reveal the challenges faced, the strategies and tools found useful, and the unintended skills that were developed along the way offering much insight to linguistic researchers, practitioners, adult L2 learners, and software developers.

Having learned a very basic level of English reading, writing, and listening only (no instruction in oral English) during Xiaolei's three middle school years (1991-1994), receiving almost no English instruction during her vocational high school years (1995-1998), and having not applied the English she learned in the almost 20 years since then, improving her English seemed a major challenge for her after they met in December 2016. Conversely, Robert had acquired only a very basic level of the Chinese language in the two 
preceding years beginning in the summer of 2014 through self-study using informal online and limited faceto-face resources. Having acquired a basic level of six other foreign languages beginning from when he was 10 years old and having lived and worked in more than 20 countries throughout his life, Robert had much knowledge and experience with learning and using foreign languages to aid him in acquiring and learning Chinese. However, he found himself struggling to find the least expensive and most effective resource for acquiring the Chinese language, reviewing the quagmire of online sources and making use of those he thought would produce his desired results with the least amount of time and effort for the six years he planned to remain in China. Robert's goal was to acquire the Chinese language for living more independently while living and working in China, so time was of the essence- he did not want to be a burden on others to communicate for him.

Xiaolei's goal was to continue learning English to allow her to learn and experience more of the world in hopes that she might someday travel to English-speaking countries. Realizing the severe limitations of the Chinese education system with regard to English language instruction, she felt very handicapped in her second language ability with being able to recall only three short phrases at the time they met each other in December 2016 "Hello," "I'm fine," and "Thank you." For the first three months of their relationship, they relied heavily on the mobile WeChat social media application and free translation applications (e.g., Baidu and iTranslate) to get them through their daily communication with each other.

Although neither of them felt the need to acquire and use each other's native language, both share the strong desire to continue learning the other's native language for the sake of improving their communication with each other and for lifelong learning. English is Xiaolei's first foreign language and Chinese is Robert's seventh. His six other foreign languages include: French, German, Greek, Spanish, Arabic, and Thai. Both share a passion for second-language acquisition and learning, and they both continue to make great strides in their efforts.

Through their own discovery over time, they realized there was no single software application that was satisfactory for them to communicate with each other without causing much anxiety and stress. For this reason, they both agreed to join forces with each other to learn more about the communication issues they faced and how to overcome them. Having worked through these many issues as a result of their newfound knowledge from the countless hours spent researching this intercultural phenomenon, they present their findings in this article to help other intercultural couples in their quest to understand and find the best strategies and tools that fit their situation while offering linguists, scholars, and researchers much insight to guide their practice and research about this much misunderstood area of language acquisition and learning.

In thinking about their past experiences with language acquisition and learning, they began to realize their situation is not unique to them as a renewed focus on second language acquisition is relatively new to education systems. Moreover, English as a Second Language (ESL) learning became fully implemented in rural schools in China only within the past 30 years and is now compulsory in Grade Three in all public schools. In addition, several studies that were conducted shed much light into specific situations as intercultural married couples looking for best solutions to stave off potential communication problems that many couples face in their initial years of marriage, and there are numerous sources that speak mostly about the problems that interracial and intercultural couples encounter with information that was not necessarily supported well with empirical findings that are very generalizable to other couples or populations [1-4]. And thus, researchers state much more research is needed in this area as we are only at the beginning of fully understanding the many nuances involved in language acquisition and use in this pragmatic area, and their affects of and on intercultural relationships.

However, those studies that were well-framed and conducted provide much insight and understanding of the real issues faced by intercultural couples wishing to establish a common language of communication [5-8]. This study also presents the various terms and theories that underpin this study to provide a more holistic view of the issues faced, the reasons for selecting and using the strategies and tools that proved most effective, and the additional skills that resulted from their second language acquisition (SLA).

Increasing the awareness and understanding of the issues interracial couples face in their daily communication and the tools and strategies they use to acquire and use their second language stand to help educators and researchers identify specific aspects of second language learning and acquisition in an applied context. From this, educators and researchers can focus their attention on aspects of ESL and SLA that matter the most in solving problems in a real-life context using the advantages that mixed-methods studies offer. While studies such as this one do not provide much generalizeablility to the larger population of intercultural couples, they do provide a degree of insight and direction to go with ESL and SLA research and practice.

As a preliminary step to any study, it is necessary to define the specific terms below that were found in the literature. As researchers mention, there are several intercultural communication contexts that apply 
ranging from friendships, business relations, marriages, ranging in social and economic topics from shopping, eating, travel and transportation, time, money, and situations that involve feelings and emotions. It is in these contexts that difficulties in communication may arise $[9,10]$. Here are just a few of the key terms that require a basic understanding in the context of this study:

Cognitive Strategies-learning strategies that require the learner to directly manipulate the learning material through "repetition, resourcing, translation, grouping, note taking, deduction, recombination, imagery, auditory representation, key word, contextualization, elaboration, transfer, and inferencing" [11]

Good Language Learner-a language learner described in terms of researchers beliefs based on a learner's personal characteristics, style, and strategies. The list provided is not all-inclusive but it includes the belief that good learners [11]:

a. Find their own way, taking responsibility for their own learning,

b. Organize information about learning,

c. Are creative, and try to feel the language by experimenting its grammar and words,

d. Create opportunities for practice in using the language inside and outside the classroom,

e. Learn to live with uncertainty by not getting confused and by continuing to talk or listen without understanding every word,

f. Use memory strategies to bring back what has been learned,

g. Make errors work for them, not against them,

h. Use linguistic knowledge, including knowledge of the first language, in learning a second language,

i. Use contextual clues to help them in comprehension,

j. Learn to make intelligent guesses,

k. Learn chunks of language as wholes and formalized routines to help them perform 'beyond their competence',

1. Learn to use certain tricks to keep conversations going,

m. Learn certain production strategies to fill in gaps in their own competence,

n. Learn different styles of speech and writing and learn to vary their language regarding the formality of the situation.

Intercultural Communication-“communication between people with differing cultural identities” [1] or, quite simply, "intercultural communication is the sending and receiving of messages across languages and cultures. It is also a negotiated understanding of meaning in human experiences across social systems and societies," as Arent [12] states. However, researchers confess it is not so simply defined. Instead, they indicate the many factors and stages that have been defined are specific to each individual case and do not apply evenly to all L2 learners in all contexts.

Language Learning Strategies-"A reflection of what the learner intends to do and the specific actions he [or she] can take" to acquire the target language [12]. Zare [12] further defines these strategies by stating that learning strategies "contribute directly to the development of the language system created by the language learner".

Second Language Acquisition a cognitive theory that "seeks to explicate the psychological mechanisms that underlie comprehension and production and the means by which that competence develops in the mind of the learner" [13].

It is widely known and recognized by researchers and practitioners that student engagement and participation in activities to help students learn and acquire a second language using a student-centered approach builds self-confidence and self-regulated/monitored learning, thus increasing their self-motivation to continue learning and acquiring the target language [10]. It is also well known that mimicry, rote memorization, and recitation of lengthy lists of words and phrases serve mainly to help students pass examinations. This was true even during Xiaolei's formative school years [14].

In Wolff's [14] study, he points to the four great lies (myths) in China that are related to English language learning. Because Xiaolei is a product of this orientation to learning English, it helps readers to know and understand the struggles she faced as a rural primary, middle, and high school student in China from the mid-1980s to early-1990s with no access to the Internet or printed English educational materials. Furthermore, the lack of necessity for Xiaolei to "master" English in her younger years for her future study or employment can be seen as indicative of most Chinese students.

In Wolff's [14] study, he addresses each myth and offers his in-depth and rational explanation for why each one is a lie that is based on fact rather than his own opinion. The first myth is the commonlyknown requirement in China that students must "master" English. Of the more than 100 dialects of English that may or may not be intelligible to speakers of other dialects, he asks: "Which dialect should they choose to master?". Moreover, he asks: "Who has ever "mastered" the English language?" and states that even those Chinese people who have a need to demonstrate their mastery of the English language are "not perfect in English". 
Addressing the second myth: "You can only make your English better by speaking with a native speaker," Wolff [14] offers this longstanding belief that many Chinese people hold today. In reality, the very limited time that Chinese spend with students in English as a Foreign Language/English as a Second Language/English Language Learning (EFL/ESL/ELL) classrooms is so little that it cannot possibly have much of an effect on their ability, especially when students are so hesitant to engage in a conversation with an English speaking foreigner; even in their native language.

He continues by addressing the third myth: "Chinglish is no good," lists all of the countries that have created their own variant of English, and asks why China has not followed suit with these countries by developing its own variant when it has the same right to do so as other countries have already done. What shall we call this variant? Chinglish or Chinese English? He closes his explanation of this myth by pointing to the same outcome as Krashen [15] states-the end goal is to communicate comprehensibly, although not perfect. Expecting mastery or perfection is setting the bar so high that it inhibits "self-confidence, intrinsic motivation, self-discipline, and develop autonomous learning skills".

Finally, Wolff [14] explains the fourth myth: "Everyone in China needs to learn English,"

thus indicating the time-honored, exam-oriented nature of Chinese education. While students spend much time listening to their teachers' lecture and taking copious notes to memorize and recite, "the curriculum is designed to teach the students all about the English language but not to learn or acquire it. For China, Wolff [14] states "it would be far more intellectually honest...to claim that everyone must study English because the current test-oriented curriculum and teaching methodology puts [English] learning and acquisition beyond reach".

As researchers have examined the stages of second language acquisition that L2 learners move through in the process of acquiring a second language, Robertson and Ford [16] expanded Krashen's [8, 16, 17] list of five stages, to the six they labeled as: (a) pre-production; (b) early production; (c) speech emergence; (d) beginning fluency; (e) intermediate fluency; and (f) advanced fluency.

Beginning with the Pre-Production stage (the silent period), the learner "takes in the language but does not speak it" [16]. During the second, Early Production, stage, the learner "begins to speak using short words and sentences" while maintaining emphasis on listening and making many errors. In the third stage, Speech Emergent, the learner's "speech becomes more frequent, but...relies heavily on contextual clues and familiar topics".

Reaching the fourth stage, Beginning Fluency, "speech is fairly fluent in social situations with minimal errors", while gaps still exist in the learner's vocabulary and phrases. During the fifth stage, Intermediate Fluency, the learner "is able to speak most fluently in new situations or academic areas" with very few gaps in vocabulary and expressions and being "able to demonstrate higher order thinking skills in the second language". In the final stage of Advanced Fluency, the learner "is essentially fluent and comfortable in communicating in the second language". Reaching this stage, Krashen [12] estimates it taking an L2 learner approximately 5-7 years to acquire a second language, while the actual time depends largely on the individual characteristics of each language learner. Robertson and Ford [16] state clearly the importance that "every ELL student comes with his or her own unique language and education background, and this will have an impact on their English learning process".

While knowledge of the stages are vital in gauging progress with second language acquisition, having knowledge of the most effective learning strategies are equally important, as individual learners will likely be "at a variety of stages in the language acquisition process" [16] and require different strategies that are mentioned on pp. 12-14. However, one of the weaknesses in the literature as it relates to this study is that most studies focus on teachers and their students in classroom settings rather than on people in mainstream society who are without instruction in a formal classroom learning environment.

Commonly known among researchers is the dialectic nature of second language acquisition. However, researchers present this dialectic view from different perspectives. While Ellis [18] mentions the dialectic of 'a conscious tension between the conflicting forces of their [L2 learners] current interlanguage productions and the evidence of feedback", other researchers recommend thinking about the intercultural communication aspect of second language acquisition as being dialectic as "the relationship between aspects of intercultural communication rather than viewing them in isolation" [9] of each other. No matter the perspective one chooses to view these dialectics, "thinking dialectically helps us to see the complexity in culture and identity" [9].

As cited in Communications [9], Martin and Nakayama (1999) list and explain six different dialectics of intercultural communication identified in their work, titled: Thinking Dialectically about Culture and Communication, to include: (a) cultural-individual; (b) personal-contextual; (c) differences-similarities; (d) static-dynamic; (e) history/past-present/future; and (f) privilege-disadvantage. These lay the foundation for addressing the interplay of intercultural communication and relationships, of which the similarities- 
differences dialectic play an important role in easing the tensions by revealing the commonalities that underpin relationships [9].

From the cognitive neuroscience perspective, Kroll [10] offers insight into the lack of research that examines differences among individuals in adult language learning and the problems facing researchers in this area. She points to the fact that "not all aspects of language processing may be sensitive to the same cognitive factors" and indicates "the development of lexicon, grammar, and phonology in a second language may follow a different course" [10], depending on a person's age of acquisition. She [10] also mentions that, while studies on the connection between music ability and second language acquisition, there may be some truth to music ability making a person more sensitive to the sound structure of a language making this factor stand out from others to "enable them to comprehend or speak words and sentences in that language"

Kroll [10] goes on to explain the mixed findings regarding the connections between working memory and second language acquisition in terms of processing speed and the speed of translation where cognates exist. While she mentions the possible effects that individual learner characteristics have on second language acquisition, the characteristics she mentions are restricted mostly to error making when translating from the native language to the second language and does not mention individual characteristics of age, sex, nationality, or other demographic factors. On the other hand, she [10] does include the work of Ullman $(2001,2004)$ as a promising direction in research as it includes "a provocative claim about why second language learning is typically more difficult for adults than for young children", differences in neural functioning for learning a second language versus learning a first language, and superior declarative memory differences among men and women being predictors of successful language learners. As with the existing literature on the stages of acquisition, most literature related to the dialectical perspectives of intercultural communication maintains a focus on classroom-based learning rather than on individual learning outside the formal classroom setting. However, knowledge of the findings and practical implications can prove helpful in an individual's understanding that can serve to help individual L2 learners make good progress in their language acquisition efforts.

In general, researchers agree that language acquisition and learning requires thinking by both students and teachers. Again, the research in this area is restricted mostly to classroom-based learning rather than on individual L2 learners in a non-academic setting. What is not mentioned across much of the literature is the role of cognition and translation, which occurs most often in L2 learners, and is focused primarily on classroom situations. When Chinese students read or listen to English, they often spend much of their time translating from English to Chinese, and then back to English to give their response, when required. This is the most basic form of translation as it occurs in L2 learning. Instead, Krashen [15] states it is more effective to learn the second language the same way they learned and acquired their native language when they were a child. Although not always grammatically correct or perfect, it most often results in comprehensible Englishthe end goal for intercultural communication in a variety of contexts. Instead, teachers spend much of their time teaching grammar which Krashen $[15,17,19]$ explains is not very vital in second language acquisitiongood grammar comes with time and experience using the language.

As compared to other contexts of the English language, communication in intercultural marital relationships is much different than that in other relationships. Because the communication topics are most often varied and unanticipated, issues arise between the two people. This is particularly evident in communication involving other family members who have never acquired the target language. Family matters involving personalities, money, property, transportation, and time come into play between the couples, their families, and friends. As such, this often changes the context and dynamics of their communication while often changing the role of each person in their communication to being a translator between their partner and his/her family. While this can be viewed as a challenge for the person translating between the two languages, this challenging role can also be viewed as a strategy for helping the L2 learner acquire the target language without realizing it. It is also worth mentioning the tendency of L2 learners to translate from the target language to their native language for making connections with what they already know is very common. This tendency and the effects it has on L2 learning and acquisition are not addressed commonly in the literature as "studies on real-time processes in second language comprehension" are still in their infancy [13].

As with learning any language, there are contextual factors that determine the stage/level of language acquisition an L2 learner of any age will achieve. While many studies examine contextual factors through an academic lens, much research in this area is focused on relationships in practical, non-academic settings. As indicated briefly in the previous section, context plays a significant role in intercultural communication. As marital relationships continue to grow, more issues between family and friends emerge and enter into conversations. While this often places a large demand on L2 learners, it can be quite healthy in the growth and acquisition of the target languages of both L2 learners. 
Robertson and Ford [16] provide a list of suggested instructional strategies for each stage of second language acquisition while focusing on the need to model the language with correct English phrasing, use appropriate gestures and body language, and avoid excessive error correction. They go on to include recommendations such as scaffolding, using cognates, providing explicit vocabulary instruction, correcting errors intentionally and appropriately, and learning the students' language. What is obvious in the literature is the focus of studies on classroom teaching and learning, with very little direction for L2 learners in nonacademic settings.

Looking specifically at the factors that influence the choice of learning strategies, Zare [11] reveals considerable information that points to L2 learners' "degree of awareness, age, sex, nationality, learning style, personality traits, motivation, learning context, and language proficiency" and mentions advanced learners using their choices more frequently. What is not mentioned the relationship between L2 learners' desired achievement level and their choice of learning strategies and cultural variation.

For the traditional college-aged Chinese students living in China, it is fair to say that most receive their college-level English education in an in-class environment. As for adult Chinese L2 learners, their options for receiving a formal English education in a physical classroom setting in China are quite limited. From this, most Chinese adults who have the desire to resume acquiring and learning a second language often resort to using mobile software applications that are either free access or require a paid annual subscription on a self-paced, self-study basis-learn as you go.

The growing choices of mobile online English learning applications are numerous, but the quality of the programs, as with any mobile second language learning application, are not regulated to a great extent, if at all. However, that does not keep them from continuing their existence. These choices include access to public WeChat programs that are mostly at no cost, and various applications that are designed mostly to translate. While the less desirable applications require devoting much time and effort, and are not very correct in their language, the more desirable applications to use are those that offer shorter segments of language teaching that are focused on specific aspects of the language. Also, the more favorable choices are those that include some sort of real-time feedback component using voice-recognition and artificial intelligence to produce pre-recorded verbal feedback to the learner. Again, because of their free or low cost, the accuracy of the feedback may be lacking.

Other strategies include reading printed books and e-books available online, and watching and listening to pre-recorded video presentations and audio books. However, choices and selections are based largely on access and cost for the available resources, not to mention individuals' motivation and acquisition levels they wish to achieve. Often times, people resort to using a strategy with which they are already familiar even though it may or may not be effective for them as an adult.

For the married couple who desire to establish a target language to communicate with each other, it is fair to say that some choose for one to learn and acquire the other's language to varying degrees while others choose to pursue learning and acquiring each other's language for enhanced communication, especially for topics that require more advanced language skills [1-4]. Realizing it takes a person 5-7 years on average to acquire fluency in a second language, a person must be persistent and patient in their language acquisition efforts.

Commonly known as the "Digital Divide," this term was first used at a time when cell personal computer technology was not yet widely available in the U.S. Thus, its meaning had a different emphasis which was on that portion of the U.S. population that did not have access to computers [9]. Soon after, the meaning expanded to include access to the Internet and cell phones. Also indicated, these troubling gaps in access still exist today, not only in many areas of developing countries like China, but also in parts of the U.S. increasing the cultural and social inequalities that have long existed in the U.S. [9]. The author [9] goes on to state "about 11 million rural Americans are unable to get [broadband] service at home" and with "so much of our daily lives online, it puts those who are not connected at a disadvantage".

In China, access to certain applications and media sources that are beneficial to L2 learning are hampered by government enforced firewalls that block access to sites, such as Facebook, YouTube, and Google. However, more people are resorting to the use of a virtual private network (VPN) to access sites and even the use of gestures and body language will to help them to acquire their second language.

\section{RESEARCH METHOD}

This autoethnographic case study employs the use of researcher constructed semi-structured interview items to solicit rich qualitative responses from both subjects, and the use of the WeChat social media platform for translating the survey items to Chinese for Xiaolei's increased understanding of each item. In addition, a handheld Sony ICD-P620 digital recorder will be used to collect verbal responses from both subjects for manual transcription to electronic documents. 
As Creswell \& Plano-Clark [20] explains, a narrative study, such as this one, "needs to find one or more individuals to study, individuals who are accessible, willing to provide information, and distinctive in their accomplishments and ordinariness or who shed light on a specific phenomenon or issue being explored". And, instead of focusing on the right questions to ask, "the focus is on the stories to emerge, recognizing that all people have stories to tell". During interviews being conducted, importance is given to data collection that involves a "wide array of procedures as the researcher builds an in-depth picture of the case" and needs to follow a protocol and, if possible, "a quiet location free from distractions" for conducting the interview. Creswell \& Plano-Clark [20] state also, "observing in a setting is a special skill that requires addressing issues such as the potential deception of the people being interviewed" and "highlights the importance of reflecting about the relationship between the interviewer and interviewee". As one form of observation, Yin [21] supports Creswell \& Planoi Clark by stating more specifically: "for case studies, 'listening' means receiving information through multiple modalities-for example, making keen observations or sensing what might be going on-not just aural modality". Although Merriam [22, 23] focuses mostly on conducting case studies in educational settings, her work lends itself to the design of this case study.

The subjects in this study are Robert and his wife, Xiaolei, living together in Linyi, China. Robert, a 56-year old American male, is an associate professor with his Ph.D. in Higher Education Research and Xiaolei, a 38-year old Chinese female, is an established writer of Chinese with a vocational high school education in China.

Following Alreck \& Settle's [24] suggestions, the researcher-constructed interview items consist of 14 open-ended statements to solicit in-depth responses from both subjects. These items are designed to focus on their personal experiences during their childhood focusing mostly on language learning while attending primary and secondary school, but also on their goals, challenges faced, and the resources they used to acquire their foreign language in adulthood.

Using sets of three interview items per session, each set will be shared with both subjects; Xiaolei via WeChat for her to think about prior to conducting each interview session, and Robert will review and respond to the items in the electronic document. During each session, each item will be read aloud before responding. Xiaolei will be the first to be interviewed for all three items, and Robert will be the last to respond to the interview items. Those items about language learning in primary and secondary school posed to Robert will focus on learning English instead of Chinese.

After completing each interview session, the digital voice files containing Xiaolei's responses will be transcribed manually to a separate electronic document, while Robert will type his responses directly into the Word document containing the interview items [24]. Xiaolei will be asked to do a member check of her responses to make any changes she finds necessary. After all sessions are complete and all digital files have been stored in the laptop computer, the documents will be analyzed to produce qualitative findings for discussion.

\section{RESULTS AND DISCUSSIONS}

The results of the qualitative analyses displayed in Tables 1 and 2 are the results of in-depth analyses of their thorough responses to the 14 interview questions, careful observations, and information collected from deep conversations about the preliminary findings from this and other relevant studies. More specifically, Table 1 provides a visual representation of the similarities and differences in the individual demographic characteristics of Robert and Xiaolei. Among the list of 27 characteristics, only 6 are similar.

In addition, Table 2 displays the intersection of the 14 themes (categories) and 45 sub-themes (subcategories) with the 3 overarching themes (categories) found during the analysis of the qualitative data.

As with most case study research, this study has assumptions and limitations. The assumptions were that all communication between Robert and Xiaolei related to the topics of this study would be completely understood by both of them, and that both would provide honest and thorough responses to the interview items. Although Xiaolei's English vocabulary was quite limited, her determination to know precisely those words and phrases that seemed unfamiliar to her coupled with her being able to confirm her understandings with Robert made these assumptions valid. The limitations of this study include the lack of generalizability to the larger population of intercultural couples, which is a trade-off for the depth and richness of their narrative responses. Therefore, it is up to the readers to determine the applicability of the findings from this study to their own unique situations, as Alreck \& Settle [24], Merriam [22, 23], and Creswell \& Plano-Clark indicate. Moreover, as the readers pour over other studies that share similar foci to this study, they are likely to arrive at similar conclusions and crossroads revealed in this study. 
Table 1. Themes (categories) and Sub-themes (sub-categories) of commonalities and differences between study participants' individual characteristics

\begin{tabular}{|c|c|}
\hline Characteristics & $\begin{array}{l}\text { Participants } \\
\text { Rober }\end{array}$ \\
\hline **Culture & Western \\
\hline$* *$ Gender & Male \\
\hline$* *$ Age & 56 \\
\hline **Position in Family & Youngest of five \\
\hline *Parental Influence & Mostly Mother \\
\hline **Family Income Level & Middle \\
\hline **Childhood Hometown & Urban \\
\hline $\begin{array}{l}* * \text { Primary and } \quad \text { Secondary } \\
\text { Schooling }\end{array}$ & Public 1 - 12(compulsory grades $\mathrm{K}-12$ ) \\
\hline$* *$ School Funding & State-funded K - 12, except school supplies \\
\hline *Public Schooling Ages & $4-17$ \\
\hline **Grade Levels Learning English & Pre-K - 12 \\
\hline$* *$ Class Size & $\sim 20$ \\
\hline$* *$ Classroom Conditions & $\begin{array}{l}\text { Central heating, cooling and lighting. Ample room for } \\
\text { seating(very good) }\end{array}$ \\
\hline
\end{tabular}

\section{**Distance to School}

\author{
**Teaching Method Used
}

**Native and *Second Language Resources While Attending Public School

**Academic Ability
**Highest Achieving Subjects
**Foreign Languages Learned And
Used
*Desire to learn and acquire the
second language
*Reasons for Continuing to Learn
and Acquire Second Language(s)
**Age Entered Workforce
**Higher Education Achieved

**Academic Ability in College

$* *$ Reading Desire

$$
\sim 1 / 2 \mathrm{~km} \quad \text { (walked every day) }
$$

Teacher-Student Participation recitation and individual; all student $\mathrm{s}$ required to speak, read, and write in print and cursive

Textbook and Printed Reading Books (Professional Weekly periodicals in Primary School, academic textbooks in middle and high school (English). Radio, phonograph, television, books, and movies (English, only) Textbook and Dictionary, only (French and German)

Low (struggled - much effort) throughout K - 12 and into first two years of college

Mathematics and Drafting

French in primary school German in high school, basic Greek, Spanish, Hebrew, Egyptian Arabic, Thai, and Mandarin Chinese

Always very motivated

To communicate more independently, lifelong learning and to communicate with my wife and her family

13 (part-time); 18 (full-time)

Continued to college at 17; completed two AS (1987,

1991) BS (2001), MEd (2004), and Ph.D (2009) degrees.

Excellent (average struggle)

Only literature that interests me; Interested mostly in the pictures rather than the words in my years; struggled with reading and I was always a slow reader until adulthood. After searching for finding ways to make increase my reading speed and comprehension, I have learned to appreciate reading more - strong desire *Learning Strategies Used and Mostly i-Phone applications, such as Panda, Oral Found Effective to Learn and Chinese (both free), Language Learning Software, and Acquire the Social Second Translation Apps, Oral Chinese book w/CD, iTranslate, Language and Chinese Dictionary

*Sense of Achievement

Mostly internal, but desire feedback from other sources. Exam scores mean very little if my own sense of achievement is not where it should be.

Xiaolei
East Asian
Female
38
Oldest of three
Mostly Mother
Low
Rural
Public Pre-K - 12(not compulsory)

State-funded 1 - 9; except school supplies family paid all tuition for high school $10-12$

$6-19$

$7-9$, none in high school

$\sim 50-60$

Noheating/cooling/lights; in primary school; brought oil lamp from home. Very crowded seating with flies (poor). No heating/cooling, but lights in middle school. Very crowded seating (less than satisfactory)

$1-2 \mathrm{~km}$ (walked every day (primary school)

$\sim 7 \mathrm{~km}$ (lived in middle school during the week, rode bicycle home every weekend)

Teacher Lecture (English) recitation by volunteer or teacher-selected (not all were required). All Students required to read and write, only

Textbook, books, readers, and radio (Chinese) Textbook and Dictionary, only (English)

\section{Above Average (not much effort)}

English, Chinese, and Geography English

Always very motivated

To broaden my horizons, communicate with my husband, and lifelong learning 19 (full-time)

No formal higher education

N/A

Strong for most all literature

Mostly i-Phone apps such as Baidu Translate, Online Media Apps such as Public WeChat, i-Translate, and others. Also, an 'English for Everyone' grammar guide, English Language Learning Software, and Dictionary

Mostly internal, but seek reassurance from others to validate my own sense of achievement.

\footnotetext{
*- Indicates similar characteristics

**. Indicates different characteristics
} 
Table 2. Matrix of themes and sub-themes from qualitative interview components

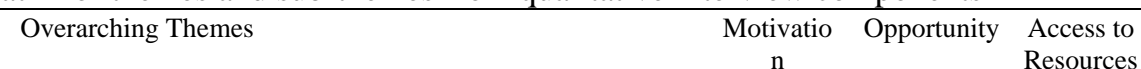

Themes and Sub-Themes from Responses to Interview Items (14) (Qualitative)

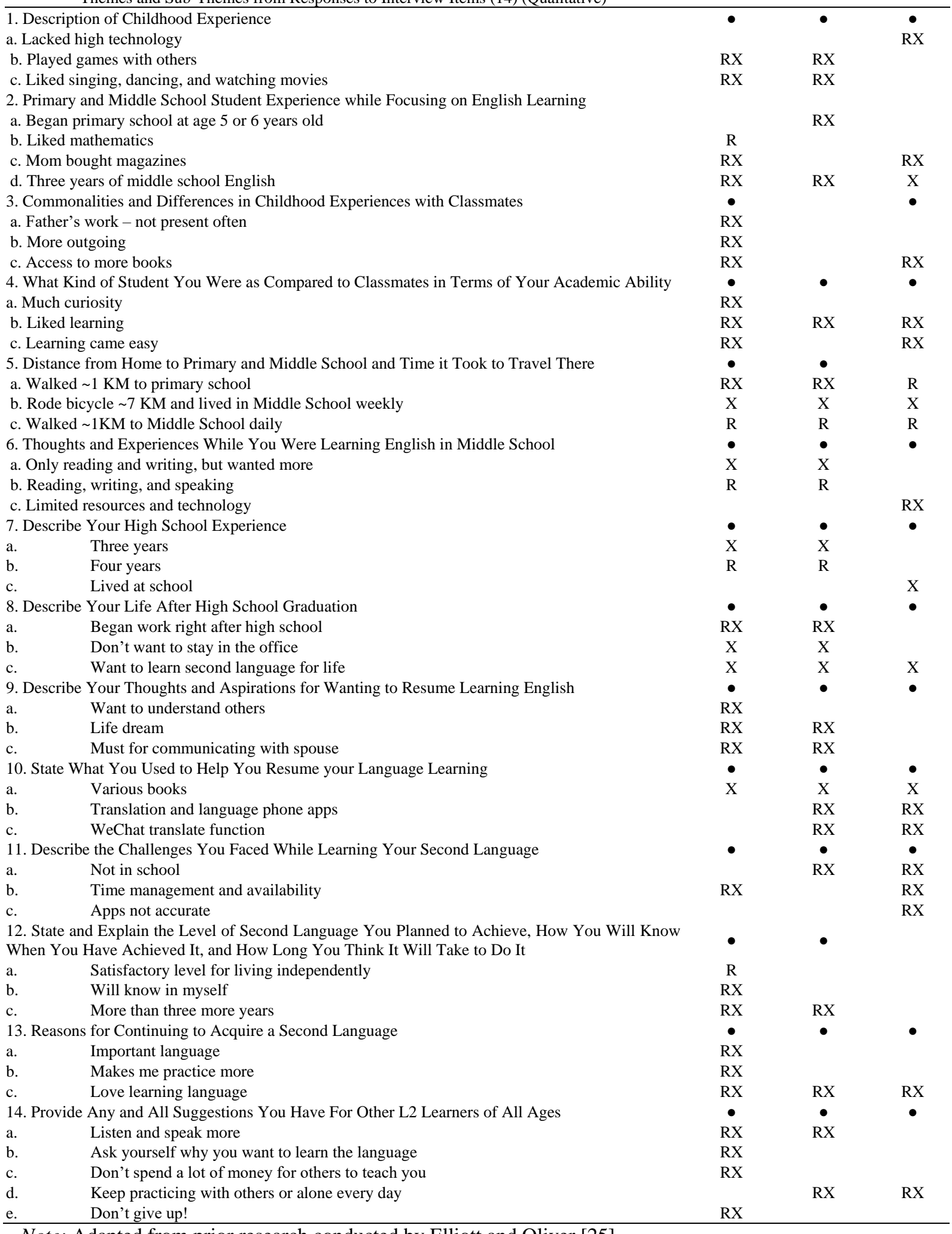

Note: Adapted from prior research conducted by Elliott and Oliver [25].

The "." indicates a theme, and the "R" (Robert) and "X" (Xiaolei) indicate a sub-theme that intersects with each overarching theme, as applicable. 
As we embarked on this journey of discovery, we couldn't help but recognize future opportunities that exist for both researchers and practitioners. While much has been accomplished, we are admittedly still in the youthful stages of fully understanding L2 learning in intercultural relationships in a continually changing environment. Future studies that move further away from the traditional classroom settings to the non-traditional home and workplace environments are certainly beneficial while continuing to look more deeply at what motivates people to learn and acquire a foreign language and how to tap into those motivational aspects in adult L2 learners. Certainly, having the apparent need and desire are what motivated Robert and Xiaolei to continue through their journey, but this motivation does not exist in all intercultural couples. For practitioners, continuing to expand their knowledge base and engaging others to explore deeply their own motivations for L2 learning and acquisition will likely result not only in maximizing their teaching and learning efforts, but will wuite possibly reveal to the L2 learners other important aspects about themselves and their intercultural relationship.

Here are a few of what were found to be the most prominent revelations from this study:

\section{a. Personal factors that promoted/inhibited language learning}

The learning environment, motivation, availability of resources, achievement level (grades and exam scores), intrinsic need to acquire the language, and sense of accomplishment seem to be important personal factors that determine the success in L2 learning and acquisition. More importantly was the need to be aware of and understand what second language theorists and researchers have found in their related studies.

\section{b. Learning strategies and tools that worked well}

Free public WeChat, TED videos, "English for Everyone" grammar book, unstructured time blocks, self-paced adding flexibility, and being challenged to translate and interpret for Robert and others seem to play a vital role in Xiaolei's L2 learning proficiency as she identified these during her reflection of her language acquisition progress.

\section{c. Learning strategies and tools that did not work well}

Time management-a busy life, trying to find time to learn and practice; lack of English-speaking environment; rare situations conversing with foreigners in English speaking environment; and the lack of structured environment for learning created the need for Xiaolei to structure her time. Likewise, with Robert's busy life as a professor and researcher, he too needed to set time and place priorities for continuing to acquire the Chinese language. Contrary to Xiaolei's target language environment, Robert continues to take advantage of opportunities to engage in conversation with others using the Chinese language-neighborhood children and adults, making purchases at local stores and gas stations, conversing with students, and the like all serve to help reinforce and improve his Putonghua.

\section{d. Factors that matter most}

Motivation-The intrinsic need is to acquire the new language for increased understanding and communication between Robert, Xiaolei, and others. Especially in light of situations that arise where certain words get in the way of what would otherwise be perceived and understood as clear communication, these specific spoken words carry much weight in the transference of important meaning. More specifically, it is often that the Chinese translation of specific words carries enough difference in cultural meaning that makes understanding the cultural context of the words critical in communicating clearly in the directness of communication.

Time and opportunity-The inherently busy social lifestyles and the perception of time and space in the minds of the Chinese people make time a premium when trying to maintain a healthy relationship. This is especially true in learning to say "No" to lunch and dinner invitations, and other activities in exchange for learning time in a society that places a demand for social gatherings an important interwoven part of daily living and creates major challenges in maintaining priorities and setting aside sufficient time for learning.

The environment-Specifically with respect to adult learning, the learning environment is less structured, and thus requires more self-discipline for L2 learners to achieve their language learning goals. With Robert's and Xiaolei's busy schedules, much was done on their own time, mostly at night in bed before going to sleep.

\section{e. Technology: its successes and limitations}

Phone technology in the times they live are of utmost importance. While computer applications are well and good, mobile technology makes access to learning resources more accessible when on-demand access is essential. However, it is found that this improving technology has the strong potential to make them lazy in their language acquisition efforts and thus increasingly dependent on this technology.

\section{f. The key to success and gauging progress}

The single key to succeeding in language acquisition is to first know and understand the factors and issues involved with second language acquisition; it's difficult, takes much time, and requires persistence to tailor the right combination of strategies and resources to fit each individual characteristics, learning style and 
goals, and flexibility of time. The self-monitoring of individual effort being expended and progress being made to achieve specific learning goals requires a flexible approach to the use of sometimes shifting patterns of strategies and tools used for acquiring the target language.

\section{g. Maintaining a positive marital relationship}

Discovering the limitations of free online and phone translation applications forced the need to find the right combination of applications to use during the initial period of their relationship. Less than optimal applications caused much confusion and anxiety for them as they struggled to find the right mix of applications, resources, and strategies to use. At these times, nothing seemed to work very well. Through their own despair, they worked together to break through the barriers that stood in their way.

Finally, both were successful through their own realization that both of them needed to make a compromise by learning each other's language to the greatest extent possible; all of this, while realizing it would take 5-7 years to acquire their second language, their age deficit, and other factors that might impede their progress toward achieving comprehensible communication between each other. Patience, love, and understanding are most important in being successful in their transformative journey to establish their third culture as a lifelong process, even when working to master a native language as part of the intercultural communication process. Working together to locate and use the correct combination of resources, while supporting each other's learning efforts as needed is equally important, while teaching each other more about their native cultures.

\section{CONCLUSION}

Having set out to examine holistically through a mixed methods study design the challenges faced by this intercultural couple, the strategies and tools they found most useful, and the unintended consequences of their efforts, it was without question a worthwhile journey for them to engage in as they continue to seek fluency in their foreign language with each other. Today, they continue to speak with each other in both languages interchangeably with the hopes that someday they might communicate with each other in their L1 language with complete comprehensibility. This phase of their relationship is only the beginning of what is yet to come, and what they have acquired from this experience has strengthened their relationship in preparation for the next steps. Their lifelong journey of learning has just begun!

\section{REFERENCES}

[1] Singleton, D and Pfenninger, S. E, "L2 proficiency as a function of cultural identity in interlingual couples," Theory and Practice of Second Language Acquisition, vol. 4(1), pp. 7-22, 2018. Retrieved from: https://www.researchgate.net/publication/327362674_L2_proficiency_as_a_function_of_cultural_identity_in_interl ingual_couples.

[2] Tili, T.R and Barker, G.G., "Communication in intercultural marriages: Managing cultural differences and conflict for marital satisfaction," Southern Communication Journal, vol. 80(3), pp. 189-210, 2015. Retrieved from: https://doi.org/10.1080/1041794X.2015.1023826.

[3] Mahadhir, M., Nor, N. F. M., Azman, H., "Communication accommodation strategies in Malaysian multiracial family interactions," Procedia - Social and Behavioral Sciences, vol. 118, pp. 259-264, 2014. Retrieved from: https://www.sciencedirect.com/science/article/pii/S1877042814015651.

[4] Ming-Fang, L., "An interlanguage pragmatic study on Chinese EFL learners' refusal: Perception and performance." Journal of Language Teaching and Research, vol. 5(3), pp. 642-653, May 2014.

[5] Chen, Y., "A cognitive linguistic approach to classroom English vocabulary instruction for EFL learners in mainland China," English Language Teaching, vol. 9(1), pp. 95-100, Mar 2009. Retrieved from: http://www.ccsenet.org/journal.html.

[6] Doyle, D., Chagal guidelines \& teaching Chinese students: Theory into practice, 2005. Retrieved from: http://archive.ecml.at/mtp2/chagal_setup/en/theory_into_practice/doyle.htm.

[7] Yilmaz, K., "The cognitive perspective on learning: Its theoretical underpinnings and Implications for classroom practices," The Clearing House, vol. 84(5), pp. 204-212, 2011. Retrieved from: https://www.researchgate.net/publication/241741103_The_Cognitive_Perspective_on_Learning_Its_Theoretical_ Underpinnings_and_Implications_for_Classroom_Practices.

[8] Zhao, C., Pandian, A., Singh, M.K.M., "Instructional strategies for developing critical thinking in EFL classrooms," English Language Teaching, vol. 9(10), pp. 14-21. 2015. Retrieved from: http://dx.doi.org/10.5539/elt.v9n10p14.

[9] Communication, Communication in the real world: An introduction to communication studies, Minneapolis MN: University of Minnesota Libraries Publishing. 2016, September. Retrieved from: http://open.lib.umn.edu/communication/.

[10] Kroll, J.F., Adult second language acquisition: A cognitive science perspective, Book Chapter in Human Behavior in Military Contexts. Washington DC: The National Academies Press. 2008.

[11] Zare, P., "Language learning strategies among EFL/ESL learners: A review of literature," International Journal of Humanities and Social Science, vol. 2(5). pp. 162-169, Mar 2012. 
[12] Arent, R., Bridging the cross-cultural gap: Listening and speaking tasks for developing fluency in English, Ann Arbor MI: University of Michigan Press. 2009.

[13] Harrington, M., Cognitive perspectives on second language acquisition, Book chapter in Robert B. Kaplan (Ed.), The Oxford Handbook of Applied Linguistics (pp. 124-140) New York: Oxford University Press. 2002. Retrieved from:https://www.researchgate.net/publication/43472643_Cognitive_perspectives_on_second_

language_acquisition? EnrichId=rgreq-49ca5ae0272ef0ac326b4428c4c286eeXXX\&enrichSource=Y292ZXJQY WdlOzQzNDcyNjQzO0FTOjIyMjgzMTk2ODI5Njk2M0AxNDMwMTM4Njg5Mzc2\&el=1_x_2\&_esc=publicatio nCoverPdf.

[14] Wolff, M., The four great lies, Book chapter in Of the Students, By the Students and For the Students, Chapter 1.2010 .

[15] Krashen, S.D., Second language acquisition and second language learning, (Internet ed.). 2002, December.

[16] Robertson, K. \& Ford, K., "Language acquisition: An overview." LD online. 2008. Retrieved from: http://www.ldonline.org/article/26751?theme=print.

[17] Krashen, S.D., Second language acquisition and second language learning, 1987. Prentice-Hall Int'l.

[18] Ellis, N.C., "Cognitive perspectives on SLA: The associative-cognitive CREED*," AILA Review, vol. 19, pp. 100121, 2006. ISSN 1461-0213 / E-ISSN 1570-5595.

[19] Krashen, S.D., Principles and practice in second language acquisition, (Internet ed.), 2009, July.

[20] Creswell, J. W and Plano-Clark, V. L, Qualitative inquiry \& research design: Choosing among five approaches, (2nd ed.). Thousand Oaks CA: Sage. 2007.

[21] Yin, R.K., Case study research: Design and methods (3rd ed.). Applied Research Methods Series, vol. 5 Thousand Oaks CA: Sage. 2003

[22] Merriam, S. B., "Qualitative research and case study applications in education." San Francisco, CA: Jossey-Bass. 1998.

[23] Merriam, S. B., Qualitative research: A guide to design and implementation, San Francisco, CA: Jossey-Bass, 2009.

[24] Alreck, P. L and Settle, R. B. The survey research handbook (3rd ed.). New York, NY: McGraw-Hill//rwin Series in Marketing, 2004.

[25] Elliott, R.W and Oliver, D. Linking faculty development to community college achievement: A mixed methods approach, Community College Journal of Research and Practice. 2015. doi:10.1080/10668926.2014.961590. 